\title{
MEIO AMBIENTE LABORAL EQUILIBRADO: ANÁLISE DO CASO BRUMADINHO ${ }^{1}$
}

\author{
Guilherme Guimaraes Feliciano ${ }^{2}$ \\ Universidade de São Paulo (USP)
}

\section{Olívia de Quintana Figueiredo Pasqualeto ${ }^{3}$ \\ Universidade Paulista (UNIP)}

\section{RESUMO}

Partindo da compreensão geral do sistema jurídico-ambiental e de suas aplicações ao direito do trabalho, este artigo discorre sobre a inefetividade dos princípios que orientam o direito ambiental - com destaque para os princípios da prevenção, da precaução, da melhoria contínua, da informação, da participação e do poluidor-pagador - que contribuem para o desencadeamento dos grandes acidentes de trabalho. Notadamente em relação à tragédia de Brumadinho (Brasil, Minas Gerais, 25/01/2019), como a correta compreensão e aplicação dos princípios jurídicos-ambientais contribuiria para evitar o acidente ou reduzir os seus efeitos? Para tanto, valendo-se dos métodos dedutivo e dialético e partindo de cuidada pesquisa bibliográfico-documental, o estudo examina: (i) o conceito de meio ambiente do trabalho; (ii) a aplicabilidade dos princípios da prevenção, precaução, melhoria contínua, informação, participação e poluidor-pagador, norteadores do direito ambiental, ao direito ambiental do trabalho; (iii) o caso Brumadinho, considerado um dos maiores acidentes do trabalho do mundo e o maior do Brasil, avaliando em que medida a inefetividade concreta

1 Os autores dedicam este artigo às famílias das vítimas de Brumadinho/MG, que - a despeito dos esforços de autoridades, envolvidos e terceiros - ainda amargam, em grande medida, um desalentador desamparo.

2 Livre-docente em Direito do Trabalho e Doutor em Direito Penal pela Faculdade de Direito da USP. Doutor em Ciências Jurídicas pela Faculdade de Direito da Universidade Clássica de Lisboa (ULISBOA). Extensão Universitária em Economia Social e do Trabalho pela Universidade Estadual de Campinas (UNICAMP). Professor associado do Departamento de Direito do Trabalho da Faculdade de Direito da USP. Juiz do Trabalho Titular da $1^{a}$ Vara do Trabalho de Taubaté. Coordenador do Curso de Pós-Graduação Lato Sensu em Direito do Trabalho e Processual do Trabalho da Universidade de Taubaté (UNITAU). Presidente da ANAMATRA (biênio 2017/2019). E-mail: dunkel2015@gmail. com

3 Doutoranda e mestra em Direito do Trabalho pela Faculdade de Direito da Universidade de São Paulo (FD/USP). Graduada em Direito pela Faculdade de Direito de Ribeirão Preto da Universidade de São Paulo (FDRP/USP). Bolsista de doutorado do programa The Ryoichi Sasakawa Young Leaders Fellowship Fund (Sylff) em 2019. Advogada. Professora universitária. 
daqueles princípios contribuiu para o evento danoso; e (iv) qual a diagnose provável da responsabilidade civil do empregador pelo desequilíbrio do meio ambiente do trabalho.

Palavras-chave: acidente de trabalho; caso Brumadinho; direito ambiental do trabalho; meio ambiente do trabalho; responsabilidade civil do empregador.

\section{BALANCED WORKING ENVIRONMENT: ANALYSIS \\ OF BRUMADINHO CASE}

\section{ABSTRACT}

Considering the general understanding of the legal-environmental system and its applications to Labour Law, this article discusses the ineffectiveness of the principles that guide Environmental Law - with emphasis on principles of prevention, precaution, continuous improvement, participation and polluter pays - competes for the deflagration of major occupational accidents. Especially in relation to the tragedy of Brumadinho (Brazil, Minas Gerais, January 25, 2019), how would the correct understanding and application of environmental legal principles contribute to avoiding the accident or mitigating its effects? In order to answer this question, using the deductive and dialectical methods and starting from careful bibliographical-documentary research, the study examines: (i) the concept of the working environment; (ii) the applicability of the principles of prevention, precaution, continuous improvement, information, participation and polluter pays, which guide Environmental Law, extending its applicability to Environmental Working Law; (iii) the Brumadinho case, considered to be one of the largest work accidents in the world and the largest in Brazil, evaluating whether the concrete ineffectiveness of those principles contributed to the harmful event; and (iv) what is the probable diagnosis of the employer's civil liability for the imbalance of the working environment.

Keywords: Brumadinho case; employer's civil liability; environmental labor law; occupational accidents; working environment. 


\section{INTRODUÇÃO}

Zelar pelo meio ambiente do trabalho e pela saúde e segurança daqueles que lá se encontram é tarefa necessária e especialmente acometida aos empreendedores - diremos até como dever acessório dos contratos individuais de trabalho ${ }^{4}$-, sobretudo quando a atividade econômica desenvolvida tem potencial de causar grandes acidentes laborais, a exemplo do desastre ocorrido pelo rompimento de barragem da mineradora Vale S/A, na cidade de Brumadinho (MG), em 25 de janeiro de 2019; ou, antes disso, do desastre de Mariana (MG), em 5 de novembro de 2015, envolvendo a BHP Billiton e a própria Vale S/A.

O caso de Brumadinho, todavia, tornou-se paradigmático. É agora considerado o maior acidente de trabalho da história do Brasil, com cerca de 240 pessoas mortas, entre as quais mais de 130 trabalhadores da mineradora Vale S/A, diretos ou indiretos (terceirizados); na comparação internacional, Brumadinho talvez seja o segundo maior desastre industrial do século XXI, perdendo apenas para o desabamento predial em Savar, na periferia de Daca, capital de Bangladesh, em que ruíram oito pisos ocupados por fábricas diversas e um centro comercial, ceifando a vida de 1.127 pessoas (não por acaso, aliás, também um desastre relacionado à exploração do trabalho humano) (NORTH, 2013).

Brumadinho não é, portanto, um caso isolado. Muitos outros desastres, no Brasil e no mundo, têm merecido a atenção dos jornais e dos especialistas, inclusive grandes acidentes industriais, a exemplo dos próprios episódios de Mariana e Savar e também dos desastres de Jesse (Nigéria, 1998), Chernobyl (Ucrânia, 1986), Bhopal (Índia, 1984) - o maior de todos, com mais de 20 mil mortes -, San Juan Ixhuatepec (México, 1984), Cubatão (Brasil, 1984), Kyushu (Japão, 1963), Shanxi e Benxi (China, 1960 e 1942), Oppau (Alemanha, 1952) e Gauley Bridge (Estados Unidos, 1927-1931). Todos esses casos têm em comum os traços característicos da grande magnitude, da letalidade multitudinária e da causalidade sistêmica, relacionada a quadros de degradação do meio ambiente (inclusive o do trabalho, na esteira do que dita, entre nós, o art. 200, VIII, da Constituição Federal).

É nesse cenário, e especialmente a partir de detalhamentos do caso Brumadinho, que discorreremos nas linhas a seguir sobre como os

4 Ou, conforme Miranda (2012), determinação inexa do negócio jurídico (com a diferença de que, no caso de um dever inexo, a determinação independe de expressa manifestação de vontade das partes por meio clausular). 
princípios informadores do direito ambiental do trabalho aplicam-se - ou deveriam se aplicar - em casos dessa natureza, e como se há de configurar a responsabilidade civil dos empregadores nos grandes acidentes em tais contextos.

Para tanto, a partir de pesquisa bibliográfica, este texto foi organizado em quatro grandes partes: (i) no primeiro item, discorre-se sobre o meio ambiente do trabalho com abordagem em seus conceitos elementares, buscando desvelar o conceito de meio ambiente adotado no âmbito do trabalho; (ii) no segundo item, debruça-se sobre os princípios jurídicos que pautarão o estudo; (iii) no terceiro item, analisa-se mais diretamente o caso Brumadinho; e (iv) no quarto item, estuda-se a responsabilização civil de empregadores em casos de desequilíbrio ambiental laboral (e, notadamente, de grandes acidentes industriais).

\section{MEIO AMBIENTE DO TRABALHO: ABORDAGEM CONCEITUAL}

A saúde e segurança dos trabalhadores, seu estudo e tratamento jurídico, não raro, são reduzidos a discussões mesquinhas sobre adicionais de insalubridade e periculosidade.

Muito além de tal monetização, contudo, a proteção do meio ambiente do trabalho - e, consequentemente, da saúde e segurança dos trabalhadores - envolve abordagens mais amplas e sistêmicas, que promovam a higidez ambiental laboral em todos os âmbitos, e evitem a concreção de todo tipo de risco, seja ele, físico (ruído, vibração, temperaturas extremas, pressões anormais, radiações ionizantes e não-ionizantes etc.), químico (poeiras, névoas, fumos, gases e vapores etc.), biológico (bactérias, fungos, helmintos, protozoários e vírus etc.), ergonômico (esforço físico, levantamento de peso, postura inadequada etc.) ou psicossocial (assédio moral, imposição e controle excessivo de metas etc.).

Tem-se já por adquirido que as questões ambientais laborais são complexas, multifatoriais e que, portanto, devem ser compreendidas a partir de uma perspectiva gestáltica ${ }^{5}$. Partindo desse entendimento, passa-se ao delineamento do que se entende por meio ambiente do trabalho, como pressuposto para as análises subsequentes.

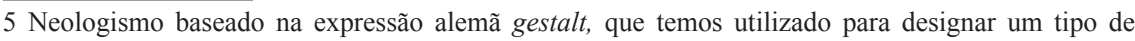
compreensão holística cujo primeiro registro reconhece a totalidade, para somente então perceber, isolar e compreender suas partes. 
Pois bem. Definir o meio ambiente do trabalho não é uma missão simples, visto tratar-se de um conceito amplo e em constante construção. Assim, neste tópico, serão traçadas algumas linhas conceituais que compõem e balizam a noção de meio ambiente do trabalho, as quais certamente evoluirão progressivamente com o avanço das tecnologias e da ciência, inclusive da ciência jurídica.

É importante frisar que o meio ambiente do trabalho faz parte do meio ambiente geral, de modo que seus conceitos estão intrinsecamente correlacionados. Dessa forma, para compreender aquele se faz necessário, antes, assimilar o conceito desse.

Conforme definição legal dada pela lei que instituiu a Política Nacional do Meio Ambiente (Lei n. 6.938, de 31 de agosto de 1981), meio ambiente é entendido como "o conjunto de condições, leis, influências e interações de ordem física, química e biológica, que permite, abriga e rege a vida em todas as suas formas". Observa-se, contudo, que tal disposição normativa (i) não expressa o caráter gestáltico do meio ambiente, já que o define como um conjunto, isto é, como a soma de elementos e não como um sistema, categoria essa que pressupõe uma necessária relação de interdependência e interconexão entre os elementos coexistentes; (ii) não inclui, no seu conceito basal, as interações de ordem psicossociais que interferem no meio ambiente. Por tais motivos, entende-se necessário complementar tal definição legal, tornando-a mais holística e adequada às características do meio ambiente.

Assim, o meio ambiente pode ser compreendido como um sistema de elementos interagentes que circundam e abrigam todas as formas de vida, inclusive a humana, impactando e sendo impactado por elas (que, aliás, são partes integrantes desse sistema). Trata-se, como resume Derani (2008), em uma perspectiva antropocêntrica, do entourage do sujeito, isto é, do seu entorno vital, daquilo que o circunda, do meio em que se encontra. Sendo tal visão centrada na vida humana, não seria possível excluir o meio laboral de sua abrangência. Há, sob esse prisma,

[...] uma indissociabilidade ontológica entre o meio ambiente natural e o meio ambiente humano, de modo que o meio ambiente - conceito e entidade - pode ser entendido como "Gestalt" ali em acepção filosófica (significando que a interpretação do objeto modifica ou condiciona a própria experiência com o objeto) e aqui em acepção fenomênica, o meio ambiente não deve ser tomado como soma de elementos a isolar, analisar e dissecar, mas como sistema constituído por unidades autônomas, manifestando uma solidariedade interna e possuindo leis próprias, donde resulta que 
o modo de ser de cada elemento depende da estrutura do conjunto e das leis que o regem, não podendo nenhum dos elementos preexistir ao conjunto (FELICIANO, 2002, p. 3).

O meio ambiente, portanto, envolve não apenas as dimensões natural, artificial e cultural, mas também a sua dimensão laboral, conforme dispõe o art. 200, VIII, da Constituição Federal, destacando constitucionalmente a dimensão ambiental laboral.

Para mais, interessa frisar que o meio ambiente do trabalho não se resume ao local de trabalho. Para além dos muros da empresa - espacial e material -, o meio ambiente do trabalho abrange também os próprios "instrumentos de trabalho, o modo de execução das tarefas" (MARANHÃO, 2017, p. 27), o clima organizacional, modalidade de pagamento, a maneira como o empregado é tratado pelo empregador e pelos seus pares (MELO, 2013), entre inúmeros outros fatores - físicos, químicos, biológicos, ergonômicos, psicossociais - que influenciam sua vida no trabalho.

Com as intensas e rápidas mudanças que ocorrem no mundo do trabalho, essa dimensão extramuros ganha cada vez mais destaque, evidenciando que o meio ambiente do trabalho não se restringe às dependências físicas do empregador, podendo se projetar em outros espaços, como na própria residência do trabalhador (a exemplo do que se verifica com aqueles que prestam trabalho à distância em sua casa, em home office), em segmentos do meio ambiente natural ou artificial (como se dá com o meio ambiente do trabalho de seringueiros ou de motoristas carreteiros, que se confundem, respectivamente, com a selva ou a rodovia) ou mesmo no ambiente virtual, assim com alguns infoproletários (FELICIANO; URIAS; MARANHÃO, 2017).

Por tudo isso, convém conceber o meio ambiente do trabalho como o sistema de condições, leis, influências e interações de ordem física, química, biológica e psicossocial que incidem sobre o homem em sua atividade laboral - o que inaugura uma concepção essencialmente funcional (e não geográfica ou espacial) -, esteja este ou não submetido ao poder hierárquico de outrem (porque, tratando-se de um direito fundamental de terceira dimensão, suas consequências não se circunscrevem ao patrimônio jurídico dos trabalhadores subordinados, embora sejam especialmente importantes nesse caso, dada a natural vulnerabilidade derivada da assimetria contratual e econômica). Um conceito simples, bem calçado na legislação em vigor e, acima de tudo, eficiente.

Por fim, é certo que, sendo parte do meio ambiente geral, o meio 
ambiente do trabalho deve ser protegido com as mesmas ênfases e os mesmos instrumentos; seu equilíbrio, essencial à qualidade de vida das pessoas, deve ser preservado e promovido, tal como previsto em normas nacionais e internacionais de máxima estatura (o art. $7^{\circ}$, XXII, e 225, caput e $\S 3^{\circ}$, da Constituição Federal; o art. 18 da Convenção Sociolaboral do Mercosul; a Convenção n. 155 da Organização Internacional do Trabalho; o art. 12 do Pacto Internacional de Direitos Econômicos, Sociais e Culturais; e assim sucessivamente). Revela-se, ainda aqui, a inexorável interdependência entre os direitos humanos fundamentais, por ser "impossível alcançar qualidade de vida sem ter qualidade de trabalho, nem se pode atingir meio ambiente equilibrado e sustentável ignorando o meio ambiente do trabalho" (OLIVEIRA, 1998, p. 78-79).

\section{DIREITO AMBIENTAL DO TRABALHO E SEUS PRINCÍPIOS NORTEADORES}

O direito ambiental do trabalho, ramo simultaneamente afeto ao direito ambiental (na sua transversalidade) e ao direito do trabalho (na sua pluricentralidade), é norteado pelos mesmos princípios jurídicos que orientam a proteção do meio ambiente lato sensu. Assim, são princípios fundantes do direito ambiental do trabalho (sem a pretensão de excluir outros frequentemente tratados na doutrina, mas que por agora não terão espaço, como o princípio do desenvolvimento sustentável ou o princípio da ubiquidade): (i) o princípio da prevenção; (ii) o princípio da precaução; (iii) o princípio da melhoria contínua; (iv) o princípio da informação-participação; e, por fim, (v) o princípio do poluidor-pagador.

Tais princípios - especialmente estes -, se interpretados combinada e sistematicamente, proporcionarão unidade ao modelo jurídico de proteção do meio ambiente do trabalho, firmando a curial necessidade de que a problemática ambiental laboral seja tratada a partir de uma visão preventiva e precautória, buscando, em um primeiro momento eliminar ou neutralizar os riscos presentes no meio ambiente do trabalho (sejam eles físicos, químicos, biológico ou psicossociais), inclusive por meio de equipamentos de proteção coletiva ou técnicas de gestão humanizada; em um segundo momento, se inviável a eliminação ou neutralização dos riscos, cumprirá reduzi-los ao menor nível economicamente possível, incorporando a utilização de equipamentos de proteção individual, que já não agem sobre a fonte de risco, mas sobre o corpo do trabalhador (Norma Regulamentadora 
n. 6); e por fim, em um terceiro momento, quando falharem os esforços de contenção anteriormente descritos, ou se não forem economicamente viáveis ou juridicamente razoáveis, buscar-se-á a monetização, relegada a situações de caráter estritamente excepcional.

Dediquemos, ainda uma vez, algum trato para cada um deles.

\subsection{O princípio da prevenção e o princípio da precaução}

Os princípios da prevenção e da precaução, apesar de semelhantes e corriqueiramente tomados como sinônimos, tecnicamente não se equivalem.

O princípio da prevenção balizou a Declaração de Estocolmo (1972) ${ }^{6}$ e pressupõe o dever público, privado e difuso - logo, extensível a todos, sejam atores púbicos ou privados - de evitar a concreção de riscos conhecidos, cientificamente comprovados e potencialmente danosos ao meio ambiente, impedindo "a ocorrência de atentados ao meio ambiente mediante meios apropriados, ditos preventivos" (PRIEUR, 2001, p. 306).

Por outro lado, com sentido diverso, o princípio da precaução aparece sintetizado no art. 15 da Declaração do Rio de Janeiro sobre Meio Ambiente e Desenvolvimento, pelo qual "quando houver ameaça de danos sérios ou irreversíveis, a ausência de absoluta certeza científica não deve ser utilizada como razão para postergar medidas eficazes e economicamente viáveis para prevenir a degradação ambiental" (ONU, 1992). Em outras palavras, ainda que não haja comprovação ou compreensão científica cabal a propósito dos riscos ambientais de determinada atividade, entende-se que há o dever, por parte dos agentes públicos ou particulares, de agir para eliminá-lo, neutralizá-lo ou ao menos minorá-lo.

Assim, ressalta-se que o ponto de divergência entre a prevenção e a precaução é a certeza científica sobre os riscos inerentes à atividade e sobre os seus possíveis danos ao meio ambiente, nele incluído o meio ambiente do trabalho. Importa ressaltar que o princípio da precaução não pretende inviabilizar ou proibir toda e qualquer atividade que cause algum tipo de impacto no meio ambiente. Com efeito, "não se trata da precaução que tudo impede ou que em tudo vê catástrofes ou males. O princípio da precaução visa à durabilidade da sadia qualidade de vida das gerações humanas à continuidade

6 Vejam-se, a propósito, os princípios n. 5 e 7. In verbis: "Princípio 5: Os recursos não renováveis da terra devem empregar-se de forma que se evite o perigo de seu futuro esgotamento e se assegure que toda a humanidade compartilhe dos benefícios de sua utilização. [...] Princípio 7: Os Estados deverão tomar todas as medidas possíveis para impedir a poluição dos mares por substâncias que possam pôr em perigo a saúde do homem, os recursos vivos e a vida marinha, menosprezar as possibilidades de derramamento ou impedir outras utilizações legítimas do mar" (ONU, 1972). 
da natureza existente no planeta" (MACHADO, 2010, p. 72), ultrapassando os pruridos da estrita cientificidade para, no marco da dúvida, proteger bens e direitos - tais como a vida e a saúde humana - que não podem esperar o avanço das ciências e das tecnologias de contenção, porque são dotados de máxima dignidade e de potencial irreparabilidade. Não por outra razão, os jusambientalistas cunharam, para o princípio da precaução, um conhecido latinismo: in dubio pro natura, a fim de resguardar o meio ambiente. E, como temos dito, tal expressão transmuda-se, no contexto ambiental laboral, para a máxima in dubio pro homine, a fim de assegurar os direitos e garantias da pessoas humana, essa ideia é usualmente evocada no campo hermenêutico - e já não no âmbito fático, como o que agora se propõe -, pelas cortes que compõem o sistema internacional de direitos humanos, como, notadamente, a de San José da Costa Rica?

\subsection{O princípio da melhoria contínua}

O princípio da melhoria contínua indica que a melhoria do meio ambiente, inclusive do meio ambiente do trabalho, deve ser buscada frequentemente, estando a par com o avanço do estado da técnica. Assim, não basta fornecer equipamentos de proteção aos trabalhadores; mais do que isso, é necessário atentar-se constantemente às novas tecnologias que eliminam, neutralizem ou ao menos reduzem mais eficazmente os riscos do meio ambiente do trabalho. Mesmo nos estritos marcos do fornecimento de equipamentos de proteção (NR n. 6), fornecê-los simplesmente não é o bastante; é preciso proporcioná-los em condições de progressiva eficácia protetiva, trocando-os por novos modelos quando do lançamento de outros mais modernos e seguros. Nesse sentido, segue o art. $7^{\circ}$, XXII da Constituição Federal, que dispõe sobre a redução de riscos inerentes ao trabalho, como também o item 6.1 do Anexo 13-A (benzeno) da Norma Regulamentadora n. 15 (sobre atividades e operações insalubres), que aborda o princípio de forma expressa:

[...] o princípio da melhoria contínua parte do reconhecimento de que o benzeno é uma substância comprovadamente carcinogênica, para a qual não existe limite seguro de exposição. Todos os esforços devem ser despendidos continuamente no sentido de buscar a tecnologia mais adequada para evitar a exposição do trabalhador ao benzeno (BRASIL, 1988, grifo nosso).

7 "El principio pro homine es un criterio hermenéutico que informa todo el derecho de los derechos humanos, en virtud del cual se debe acudir a la norma más amplia, o a la interpretación más extensiva, cuando se trata de reconocer derechos protegidos e, inversamente, a la norma o a la interpretación más restringida cuando "se trata de establecer restricciones permanentes al ejercicio de los derechos o su suspensión extraordinaria" (PINTO, 1997. p. 163 e ss). 
É, ademais, o que decorre do art. 12 da Convenção n. 155 da Organização Internacional do Trabalho, com força supralegal no ordenamento brasileiro, à vista da aprovação pelo Decreto Legislativo n. 2/1992 e da publicação pelo Decreto n. 1.254, de 29/9/1994, da Presidência da República, como também da jurisprudência lançada há dez anos pelo Supremo Tribunal Federal (Habeas Corpus n. 77.631-5/SC). Com efeito, reza o art. 12 da Convenção n. 155 que os Estados-partes deverão adotar

[...] medidas de conformidade com a legislação e a prática nacionais a fim de assegurar que aquelas pessoas que projetam, fabricam, importam, fornecem ou cedem, sob qualquer título, maquinário, equipamentos ou substâncias para uso profissional [...] c) façam estudos e pesquisas, ou se mantenham a par de qualquer outra forma, da evolução dos conhecimentos científicos e técnicos necessários para cumprir com as obrigações expostas nos itens a) e b) do presente artigo (grifo nosso) ${ }^{8}$.

Não há dúvidas, portanto, de que o princípio da melhoria contínua integra o ordenamento jurídico em vigor. Há que fazê-lo valer, inclusive judicialmente.

\subsection{Os princípios da informação e da participação}

Para que haja efetiva observância dos princípios analisados acima, é preciso que todos aqueles que participam do meio ambiente colaborem para a sua preservação. Assim também se dá no meio ambiente do trabalho, no qual todos os atores envolvidos devem colaborar para a manutenção de seu equilíbrio, inclusive os trabalhadores. Neste tocante, merecem atenção os princípios da informação e da participação, segundo o qual, a uma, os trabalhadores têm o direito de participar das decisões tomadas sobre o meio laboral, tal como ocorre nas Comissões Internas de Acidentes do Trabalho (CIPA), reguladas entre nós pela Norma Regulamentadora n. 5; e, da mesma maneira, para que essa participação seja possível, adequada e não meramente pro forma, é preciso que se lhes garanta acesso à totalidade das informações sobre as questões ambientais laborais, o que consubstancia,

8 As alíneas a e b do art. 12 dispõem, respectivamente, que os Estados-partes assegurem, da parte dos que projetam, fabricam, importam, fornecem ou cedem, sob qualquer título, maquinário, equipamentos ou substâncias para uso profissional, que tenham a certeza, na medida do razoável e possível, de que o maquinário, os equipamentos ou as substâncias em questão não implicarão perigo algum para a segurança e a saúde das pessoas que fizerem uso correto dos mesmos; e que facilitem informações sobre a instalação e utilização corretas do maquinário e dos equipamentos e sobre o uso correto de substâncias, sobre os riscos apresentados pelas máquinas e os materiais e sobre as características perigosas das substâncias químicas, dos agentes ou dos produtos físicos ou biológicos, assim como instruções sobre a forma de prevenir os riscos conhecidos. 
para o empregador, um dever acessório inarredável de prestar informações aos trabalhadores sobre o meio laboral em que se inserem. Tal dever consta, a propósito, do rol de deveres do empregador previsto no item 1.7 da Norma Regulamentadora n. 1, segundo a qual

\subsection{Cabe ao empregador:}

a) cumprir e fazer cumprir as disposições legais e regulamentares sobre segurança e medicina do trabalho;

b) elaborar ordens de serviço sobre segurança e saúde no trabalho, dando ciência aos empregados por comunicados, cartazes ou meios eletrônicos.

c) informar aos trabalhadores:

I - os riscos profissionais que possam originar-se nos locais de trabalho;

II - os meios para prevenir e limitar tais riscos e as medidas adotadas pela empresa; III - os resultados dos exames médicos e de exames complementares de diagnóstico aos quais os próprios trabalhadores forem submetidos;

IV - os resultados das avaliações ambientais realizadas nos locais de trabalho. $[\ldots]$

Nesse mesmo sentido, ademais, dispõe o art. 13 da Convenção n. 161 da Organização Internacional do Trabalho, pelo qual "todos os trabalhadores devem ser informados dos riscos para a saúde inerentes a seu trabalho". Para tanto, a informação transmitida aos trabalhadores deve ser clara e objetiva, com linguagem acessível e amplamente divulgada (CLERC, 1982).

Acolhendo tal princípio, a Norma Regulamentadora n. 9 (Programa de Prevenção de Riscos Ambientais) faz menção expressa, em seu item 9.5.2, ao direito de informação do trabalhador, dispondo que "os empregadores deverão informar os trabalhadores de maneira apropriada e suficiente sobre os riscos ambientais que possam originar-se nos locais de trabalho e sobre os meios disponíveis para prevenir ou limitar tais riscos e para proteger-se dos mesmos".

\subsection{O princípio do poluidor-pagador}

Por fim, caso o dano ambiental - nele incluído os danos ambientais laborais - se concretize, malogrando o binômio prevenção e precaução, opera indelevelmente o princípio do poluidor-pagador, de extrema relevância para o tema da responsabilidade civil do empregador em caso de acidentes de trabalho e doenças ocupacionais. Por força desse princípio, aquele que poluir o meio ambiente terá a obrigação ex delicto de indenizar - de internalizar o custo indevidamente externalizado -, tanto pelos danos 
causados ao meio ambiente, como a terceiros. Nesse sentido, aquele que causar desequilíbrios no meio ambiente do trabalho deverá arcar com os custos derivados da degradação engendrada. Tal mandamento é expresso na Lei n. 6.938/81, em seu art. $4^{\circ}$, VII, segundo deve-se impor ao poluidor ambiental a "obrigação de recuperar e/ou indenizar os danos causados e, ao usuário, da contribuição pela utilização de recursos ambientais com fins econômicos".

\section{GRANDES ACIDENTES E MEIO AMBIENTE DO TRABALHO: ANALISANDO O CASO BRUMADINHO}

Em 25 de janeiro de 2019, numa fatídica sexta-feira, espalhava-se pelo Brasil e por todo o mundo a notícia de que mais uma barragem de rejeitos da mineradora Vale se rompia no Estado de Minas Gerais, agora na cidade mineira de Brumadinho, repetindo a história da vizinha Mariana (MG), que há poucos anos também havia sido inundada por lama. Em Brumadinho, no entanto, as perdas humanas foram maiores: cerca de 240 pessoas mortas foram contabilizadas até o presente momento, o que inclui mais de 130 trabalhadores da mineradora. Deu-se, com efeito, o rompimento da barragem 1 da Mina Córrego do Feijão, seguindo-se um curso caudaloso de toneladas de lama que atingiu boa parte da área administrativa da Vale e da comunidade da Vila Ferteco (em Brumadinho), deixando rastro sem precedentes de destruição ambiental e centenas de mortes.

Houve danos a todo o meio ambiente, seja em seu aspecto natural (já que a vegetação, a fauna e o solo da localidade foram degradados e a lama atingiu o rio Paraopeba), no artificial (com a destruição de moradias, pensões e logradouros) e, em especial, em sua dimensão laboral (com a morte das várias dezenas de trabalhadores da Vale que se encontravam no prédio da mineradora).

O desastre de Brumadinho - indubitavelmente um grande acidente industrial, na acepção técnica da Convenção n. 174 da Organização Internacional do Trabalho (aprovada pelo Decreto Legislativo n. 246/2001 e publicada pelo Decreto n. 4.085/2002) - já pode ser considerado como o maior acidente do trabalho da História do Brasil, como pontuamos alhures. De acordo com a Convenção da Organização Internacional do Trabalho n. 174, entende-se por acidente maior 
[...] todo evento inesperado, como uma emissão, um incêndio ou uma explosão de grande magnitude, no curso de uma atividade dentro de uma instalação exposta a riscos de acidentes maiores, envolvendo uma ou mais substâncias perigosas e que exponha os trabalhadores, a população ou o meio ambiente a perigo de consequências imediatas ou de médio e longo prazos.

No caso de Brumadinho, contudo, decerto não houve apenas um infeliz infortúnio. As investigações realizadas após o desastre apontam inúmeras irregularidades na barragem rompida. Vejamos alguns poucos aspectos.

Segundo o Fórum Nacional da Sociedade Civil na Gestão de Bacias Hidrográficas (FONASC-CBH), havia inconsistências no processo de licenciamento, já que a empresa se valeu do Licenciamento Ambiental Concomitante (LAC) ${ }^{9}$, ante decisão administrativa do Governo de Minas Gerais garantindo que empreendimentos de mineração de grande porte, antes de classe 6 de risco, fossem enquadrados como de classe 4 (sujeitos a procedimentos mais simples). Essa manobra incrementou o risco de rompimento da barragem.

De outra parte, o Estudo de Impacto Ambiental (EIA) desenvolvido para o projeto de Brumadinho, como apresentado em audiências públicas de março de 2019, não continha a correta delimitação da Área de Influência Direta (AID). A ampliação do empreendimento previa ainda a supressão de vegetação em Área de Preservação Permanente (APP), na zona de amortecimento do Parque da Rola Moça, atentando contra a biodiversidade local.

Chama ainda a atenção o fato de que, para além das barragens, a Mina Córrego do Feijão apresentava várias estruturas administrativas e de apoio muito próximas à principal área de risco, como o centro administrativo, $o$ refeitório e várias oficinas de manutenção, além de terminal de carregamento e de uma pequena malha ferroviária para escoamento do minério de ferro. Todas essas estruturas estavam no curso provável da lama, caso houvesse - como houve - um rompimento.

Destaque-se ainda a falha das sirenes de segurança, que deveriam ter sido acionadas para alertar trabalhadores e moradores vizinhos do deslizamento, como previa o Plano de Ação de Emergência de Barragens de Mineração, nos termos do art. $8^{\circ}$, VII, da Lei n. 12.334/2010, que estabelece a Política Nacional de Segurança de Barragens. As sirenes, todavia, não funcionaram, como se soube por testemunhas e ulteriormente pela própria Vale (ROSSI, 2019).

9 No Licenciamento Ambiental Concomitante (LAC) serão analisadas as mesmas etapas previstas no Licenciamento Ambiental Trifásico, com a expedição concomitantemente de duas ou mais licenças (diferentemente do Licenciamento Ambiental Trifásico (LAT), em que a Licença Prévia, a Licença de Instalação e a Licença de Operação da atividade ou do empreendimento são concedidas em etapas sucessivas). 
Por fim, apontem-se as recomendações da Academia Nacional de Engenharia em relação à potencial inadequação do método de construção de barragem por alteamento a montante, utilizado em praticamente todas as barragens da Vale no território mineiro. Embora mais barato e frequente, o método de alteamento a montante é o de maior risco, porque a barragem é construída em cima dos próprios rejeitos. Esse risco diminui em regiões potencialmente secas (e é essa a hipótese mais comum de seu emprego pelo mundo afora); mas jamais foi esse o caso de Minas Gerais, notadamente nas regiões de Brumadinho ou de Mariana, ante o clima úmido e os índices pluviométricos altos, que exatamente desaconselhavam a técnica (PASSARELLI, 2019).

$\mathrm{Na}$ verdade, o método de alteamento a montante está associado à maioria dos desmoronamentos de barragens de rejeitos em todo o mundo. $\mathrm{O}$ método mais adequado para Brumadinho e Mariana seria o de alteamento a jusante, mais seguro e previsível, notadamente porque a barragem se ergue sobre solo mais firme: não se empegam rejeitos consolidados para os alteamentos. Grosso modo, o método de jusante apresenta maior "resistência a carregamentos dinâmicos, [o que se deve] ao fato de escalonar a construção sem interferir na segurança, [e] dessa forma facilita a drenagem, possui baixa susceptibilidade de liquefação e simplicidade na operação" (CARDOZO; PIMENTA; ZINGANO, 2017). Nada obstante, é também o método mais caro e de maiores impactos ambientais durante a construção. A Tabela 1 bem demonstra a sua melhor serventia à hipótese de Brumadinho.

Tabela 1 Resumo comparativo dos principais métodos construtivos de barragens de rejeitos

\begin{tabular}{|l|l|l|l|}
\hline & Montante & Jusante & Linha de centro \\
\hline Tipo de rejeito & $\begin{array}{l}\text { Baixa densidade para que } \\
\text { ocorra segregação. }\end{array}$ & Qualquer tipo. & $\begin{array}{l}\text { Areias de } \\
\text { lamas de baixa } \\
\text { plasticidade. }\end{array}$ \\
\hline Descarga de rejeitos & Periférica. & Independe. & Periférica. \\
\hline $\begin{array}{l}\text { Armazenamento de } \\
\text { água }\end{array}$ & $\begin{array}{l}\text { Não recomendável para } \\
\text { grandes volumes. }\end{array}$ & Bom. & Aceitável. \\
\hline $\begin{array}{l}\text { Resistência a abalos } \\
\text { sísmicos }\end{array}$ & Baixa. & Boa. & Aceitável. \\
\hline Alteamentos & Ideal menos 10 m/ano. & Nenhuma restrição. & Pouca restrição. \\
\hline Vantagens & $\begin{array}{l}\text { Menor custo, utilizado onde } \\
\text { há restrição de área. }\end{array}$ & Maior segurança. & $\begin{array}{l}\text { Flexibilidade } \\
\text { construtiva. }\end{array}$ \\
\hline
\end{tabular}




\begin{tabular}{|l|l|l|l|}
\hline Desvantagens & $\begin{array}{l}\text { Baixa segurança } \\
\text { suscetibilidade a liquefação } \\
\text { e piping. }\end{array}$ & $\begin{array}{l}\text { Grande quantidade } \\
\text { de material } \\
\text { requerido proteção } \\
\text { do talude a } \\
\text { jusante apenas na } \\
\text { configuração final. }\end{array}$ & $\begin{array}{l}\text { Necessidade de } \\
\text { eficiente sistema } \\
\text { de drenagem. }\end{array}$ \\
\hline
\end{tabular}

Fonte: Cardozo, Pimenta e Zingano (2017).

Não se fez, portanto, a olhos vistos, a melhor escolha.

Tantas condutas desviantes, aliadas à falta de fiscalização e à falta de manutenção da barragem, resultaram em mortes e em desequilíbrio do meio ambiente, nele considerado o do trabalho. Eis o dramático ensejo do tudo quanto dizíamos nos tópicos anteriores: malograda a prevenção e a precaução, restará agora identificar os responsáveis, para efeitos de responsabilidade criminal e civil, inclusive na perspectiva da responsabilização patronal ambiental laboral, a fim de dar concretude ao princípio do poluidor-pagador.

\section{4 (DES)EQUILÍBRIO AMBIENTAL LABORAL, GRANDES ACIDENTES E RESPONSABILIDADE CIVIL DO EMPREGADOR}

Dita o art. 927 do Código Civil que todo aquele que provoca dano a outrem fica obrigado a repará-lo. Assim também se dá em relação ao meio ambiente, nele incluído o do trabalho, mas pela lógica própria do princípio do poluidor-pagador. Nessa particular perspectiva, todo aquele que degrada e, portanto, desequilibra o meio ambiente do trabalho, deve indenizar, tanto pelos danos coletivos como pelos danos individuais (ou, na acepção do art. $14, \S 1^{\circ}$, da Lei n. 6.938/1981, tanto pelos danos "ao meio ambiente" como pelos danos "a terceiros"). É o que provem do próprio art. $225, \S 3^{\circ}$ da Constituição Federal, ao dispor que "as condutas e atividades consideradas lesivas ao meio ambiente sujeitarão os infratores, pessoas físicas ou jurídicas, a sanções penais e administrativas, independentemente da obrigação de reparar os danos causados" (grifo nosso).

A parte final do dispositivo remete à legislação infraconstitucional, constituindo hipótese de melhoria da condição social dos trabalhadores urbanos e rurais vitimados por acidentes de trabalho e doenças ocupacionais, nos exatos termos do art. $7^{\circ}$, caput, in fine, da Constituição Federal (o que permite excepcionar, pelo princípio da norma mais favorável - que define a hierarquia dinâmica das fontes formais do Direito do Trabalho -, 
a regra restritiva do inciso XXVIII, quanto à responsabilidade civil do empregador apenas "quando incorrer em dolo ou culpa"). E o diploma legal a disciplinar a responsabilidade por danos ao meio ambiente (inclusive o do trabalho) no Brasil é precisamente a Lei n. 6.938/1981, há pouco citada, que instituiu a Política Nacional do Meio Ambiente. Reza o seu art. 14, § $1^{\circ}$, também já reportado: "Sem obstar a aplicação das penalidades previstas neste artigo, é o poluidor obrigado, independentemente da existência de culpa, a indenizar ou reparar os danos causados ao meio ambiente e a terceiros, afetados por sua atividade" (grifo nosso).

Nessa precisa lógica,

[...] quando o "habitat laboral" se revela inidôneo a assegurar condições mínimas para uma razoável qualidade de vida do trabalhador, teremos aí uma lesão ao meio ambiente do trabalho, e esse complexo de bens materiais e imateriais pode ser agredido e lesado tanto por fontes poluidoras externas como internas, provenientes de outros empreendimentos, trazendo à tona, inclusive, a questão da responsabilização pelos danos, uma vez que os danos ao meio ambiente do trabalho não ficam restritos ao ambiente em que o trabalhador exerce seu labuto, mas o acompanham após o fim do expediente (PADILHA, 2013, p. 181).

Observe-se, portanto, que em matéria ambiental, aquele que polui o meio ambiente fica obrigado a repará-lo independentemente da existência de culpa, o que consubstancia, por definição, a hipótese de responsabilidade civil objetiva do poluidor. Ora, se o meio ambiente do trabalho é parte integrante do meio ambiente geral (art. 200, VIII, Constituição Federal), a conclusão é inapelável: a responsabilidade civil objetiva aplica-se a todo empregador que promova sua atividade econômica em condições de desequilíbrio ambiental laboral, isto é, em situação de desequilíbrio sistêmico, com efeitos danosos para o próprio meio ambiente ou para terceiros.

Mas o que dizer, então, da parte final do inciso XXVIII do art. $7^{\circ}$ da Constituição Federal, ao dispor sobre o direito de todo trabalhador a receber "seguro contra acidentes de trabalho, a cargo do empregador, sem excluir a indenização a que este está obrigado, quando incorrer em dolo ou culpa"? Há também hipóteses de responsabilidade civil de tipo aquiliano nos supostos da infortunística do trabalho? Ou, pelo contrário, operou-se uma expressiva mutação constitucional que redundou, na prática, em se superar a letra posta pelo constituinte originário há mais de trinta anos?

Essa celeuma que contrapõe as possibilidades de responsabilidade civil subjetiva do empregador às de responsabilidade objetiva do poluidor, dá conteúdo a uma das mais conhecidas antinomias do Direito ambiental 
do trabalho. É, porém, uma antinomia aparente, pelas exatas razões que se passa a demonstrar.

A responsabilidade civil subjetiva do empregador - isto é, aquela derivada da existência de dolo ou culpa a informar a sua conduta (quando pessoa natural) ou a de seus prepostos e representantes, a exemplo do art. $7^{\circ}$, XXVIII, da Constituição Federal - verificar-se-á, na prática, quando a lesão decorrer de hipótese de causalidade tópica (causalidade não difusa, de encadeamento univetorial, disparada por fatos determinados no espaço-tempo), e não de causalidade sistêmica, como temos sempre sustentado. Assim são os cursos causais monolineares, que não têm magnitude para desequilibrar o meio ambiente laboral. Suponha-se um acidente de trajeto ocorrido em razão de avaria oculta intencionalmente nas dependências da empresa, por preposto do empregador, no automóvel do empregado; ou então o acidente de trajeto ocorrido por imprudência pessoal do condutor contratado pela empresa, em situação de transporte coletivo oferecido para os seus empregados. Nas duas situações, identifica-se o elemento subjetivo da conduta (o dolo no primeiro caso e a culpa no segundo caso); e o empregador responderá pelos danos, na forma do art. 933 do Código Civil, "ainda que não haja culpa de sua parte" (mas haverá a culpa lato sensu do preposto, empregado ou serviçal, ao exercitar o trabalho que lhes competir, nos exatos termos do art. 932, III do Código Civil).

Já nos casos de poluição ambiental laboral (desequilíbrio sistêmico do meio ambiente do trabalho), a responsabilidade do poluidor será objetiva, como já asseverado. E quem será o poluidor? Será toda "pessoa física ou jurídica, de direito público ou privado, responsável, direta ou indiretamente, por atividade causadora de degradação ambiental" (art. $3^{\circ}$, IV, da Lei n. 6.938/1991); logo, por excelência e pertinência, o poluidor ambiental laboral será geralmente o empregador (embora também possa sê-lo, sob dadas circunstâncias, os próprios empregados ou terceiros). Em todo caso, o poluidor fica obrigado a reparar os danos causados ao meio ambiente do trabalho e aos trabalhadores, independentemente de culpa ou dolo.

A fim de identificar um meio ambiente laboral poluído, temos sugerido um rol exemplificativo de indícios que sinalizam causalidades sistêmicas (FELICIANO, 2013): (i) a afetação multitudinária dos trabalhadores, uma vez que todos estão sujeitos às mesmas condições ambientais agressivas (em casos de insalubridade, periculosidade ou penosidade não controladas) e por isso, tendem a sofrer lesões semelhantes (PADILHA, 2002); (ii) a inércia lesiva, demonstrada por autuações administrativas anteriores 
com objeto igual ou similar àquele discutido nos autos; (iii) a imperícia organizacional (que não se confunde com a imperícia modalidade de culpa stricto sensu), comumente verificável em casos de mudança recente do objeto social da empresa; e (iv) a constatação pericial de riscos agravados ou proibidos naquele meio ambiente do trabalho (porque o risco tem dimensão fenomênica, podendo ser aferido, comparado e quantificado). Para ilustrar a danosidade sistêmica e contrapô-la à tópica, relatamos duas situações, ambas extraídas da casuística forense:

\begin{abstract}
Imagine-se, e. g., a hipótese de um trabalhador sequelado por choque elétrico porque o seu encarregado esqueceu-se de colocar, na chave geral, o cadeado de segurança, vindo um terceiro a energizar acidentalmente o equipamento em conserto. Todos os procedimentos de segurança são, em geral, observados, ocupando-se a empresa de distribuir EPI bastantes, além de orientar e fiscalizar o uso (Súmula n. 289 do C. TST). O acidente deveu-se, claramente a uma falha humana, não a um quadro de desequilíbrio organizacional ou ambiental. Logo, terá havido causalidade tópica, a atrair a norma do art. $7^{\circ}$, XVIII, da CRFB [...]. De outra parte, imagine-se que auditores fiscais do trabalho [...] identifiquem cerca de duas dezenas de trabalhadores portadores de disacusia neurossensorial bilateral, todas lotados na mesma seção de certa indústria metalúrgica. Perícias ambientais detectaram níveis locais de ruído variáveis entre 86,6 e 88,0 decibéis, enquanto perícias médicas revelaram que as perdas bilaterais dos empregados oscilam entre $13,52 \%$ e $16,21 \%$. No processo judicial em que se reclamam indenizações individuais, as testemunhas ouvidas revelam o fornecimento insuficiente de protetores auriculares, aliado à inocorrência de orientação ou de efetiva fiscalização de uso. Aí estão suficientemente descritos elementos indicativos da causalidade sistêmica dos danos, a atrair a norma do art. 14, $\S 1^{\circ}$, da Lei n. 6.938/81 (FELICIANO, 2013, p. 22-23).
\end{abstract}

Nota-se, a partir dos exemplos traçados acima, que, em contraposição à causalidade tópica, a causalidade sistêmica ensejadora de poluição ambiental laboral tem relação direta com a própria organização do meio ambiente do trabalho, com os métodos de produção e com o desrespeito reiterado de obrigações legais (haja ou não subjetividades que mereçam reprimenda, como nos casos de culpa).

Cumpre aqui, ademais, estabelecer uma distinção. Mesmo em casos de causalidade tópica, haverá responsabilidade civil objetiva do empregador enquanto a atividade econômica por ele desenvolvida, em função de suas peculiaridades, oferecer riscos especialmente elevados aos trabalhadores, isto é, riscos superiores àqueles suportados pelos demais sujeitos que se aproveitam, direta ou indiretamente, daquela atividade. É o que dispõe o parágrafo único do art. 927 do Código Civil, segundo o qual "haverá 
obrigação de reparar o dano, independentemente de culpa, nos casos especificados em lei, ou quando a atividade normalmente desenvolvida pelo autor do dano implicar, por sua natureza, risco para os direitos de outrem". Esses não são riscos incrementados ou proibidos, como os que definem a responsabilidade civil objetiva ambiental laboral (art. 14, $\S 1^{\circ}$, da Lei n. 6.938/1981); mas são riscos inerentes superlativos, como os temos denominado, por deflagrarem uma outra hipótese de responsabilidade civil patronal objetiva, fora das situações de desequilíbrio do meio ambiente do trabalho. Não foi outra a interpretação dada pelo Centro de Estudos Judiciários do Conselho da Justiça Federal, durante a I Jornada de Direito Civil (2002), expressa em seu Enunciado n. 38:

A responsabilidade fundada no risco da atividade, como prevista na segunda parte do parágrafo único do art. 927 do novo Código Civil, configura-se quando a atividade normalmente desenvolvida pelo autor do dano causar a pessoa determinada um ônus maior do que aos demais membros da coletividade (grifo nosso).

É a hipótese do segurança patrimonial alvejado em serviço (supondo-se atendidas todas as normas de saúde e segurança do trabalho aplicáveis à sua atividade $)^{10}$, ou da tripulação morta em queda de aeronave que se deveu ao fortuito ou força maior.

Assim, e em síntese, podemos identificar três situações jurídicas distintas e complementares com respeito à responsabilização civil do empregador por acidentes do trabalho ou doenças ocupacionais: (i) responsabilidade civil subjetiva do empregador, calcada em dolo ou culpa, nos casos

10 Cf., por todos, TST, RR n. RR-121500-82.2010.5.17.0002, $7^{\mathrm{a}}$ T., rel. Min. VIEIRA DE MELLO FILHO, j. 9.3.2016. In verbis: "RECURSO DE REVISTA - DANO MORAL - EMPREGADO VÍTIMA DE ASSALTO - TRANSPORTE DE VALORES - EMBOSCADA - VEÍCULO ALVEJADO POR ARMA DE FOGO - ÓBITOS DE COLEGAS - ABALO PSICOLÓGICO - ATIVIDADE DE RISCO - RESPONSABILIDADE OBJETIVA. O art. $7^{\circ}$, caput, da Constituição Federal, ao instituir os direitos dos trabalhadores, deixa expresso que aquele rol é o patamar civilizatório mínimo assegurado a quem disponibiliza a sua força de trabalho no mercado econômico, razão pela qual a regra inserta no inciso XXVIII do referido dispositivo constitucional não elide a incidência de outro sistema de responsabilidade civil mais favorável ao empregado. Essa é a hipótese do art. 927, parágrafo único, do Código Civil, que deve incidir todas as vezes em que a atividade desenvolvida pelo empregado na empresa ocasionar riscos superiores àqueles inerentes ao trabalho prestado de forma subordinada, como ocorre no caso dos autos, em que o transporte de valores, mesmo com a utilização de todos os meios preventivos recomendados pelas autoridades de segurança pública, permitiu a ocorrência de lesão à integridade física do empregado, vítima de assalto a mão armada, sofrendo violência e vivenciando momentos de terror. Na hipótese dos autos, afiguram-se presentes os três elementos necessários à responsabilização do empregador, quais sejam: (i) atividade que, considerando-se a teoria do risco adquirido, representa perigo a direito de outrem (equivalente à conduta, se o autor do dano fosse pessoa física); (ii) vilipêndio a direito da personalidade do empregado, consubstanciado na sua integridade física, ou seja, dano à sua esfera juridicamente protegida; e (iii) nexo causal. Inseriuse, pois, na atividade empresarialmente explorada, motivo pelo qual à outra conclusão não se pode chegar, senão a de que o empreendimento em questão foi a causa determinante do dano gerado ao empregado. Recurso de revista conhecido e provido". 
de danos de causalidade tópica, (art. $7^{\circ}$, XXVIII, Constituição Federal; art. 186 e 927, caput, do Código Civil); (ii) responsabilidade civil objetiva do empregador, independentemente de dolo ou culpa, decorrente de um risco especialmente elevado (risco inerente superlativo) que deriva de sua atividade econômica (art. 927, parágrafo único, Código Civil); e (iii) responsabilidade civil objetiva do empregador, independentemente de dolo ou culpa, decorrente do desequilíbrio do meio ambiente ou poluição ambiental laboral (art. 14, $\S 1^{\circ}$, da Lei n. 6.938/1981, aplicável nos casos de danosidade sistêmica).

No caso dos grandes acidentes industriais, como foi o dantesco episódio de Brumadinho, a responsabilidade civil do empregador pelos danos causados aos trabalhadores será tendencialmente objetiva, seja pela hipótese (ii) de risco inerente superlativo, seja pela hipótese (iii) de poluição ambiental laboral. Tem-se um exemplo do primeiro caso nos acidentes ocorridos em instalações nucleares e fábricas de tratamento de substâncias radioativas (que sequer são alcançados pela Convenção da Organização Internacional do Trabalho n. 174, por efeito do art. $1^{\circ}, 3, a$. Será exemplo do segundo caso todo aquele acidente que, subsumível à Convenção da Organização Internacional do Trabalho n. 174, ocorre no âmbito de "instalação exposta a risco de acidentes maiores", assim entendida "aquela que produz, transforma, manipula, utiliza, descarta ou armazena, de maneira permanente ou transitória, uma ou várias substâncias ou categorias de substâncias perigosas, em quantidades que ultrapassem a quantidade limite" fixada pela legislação nacional $\left(\operatorname{art} .3^{\circ}, c\right)$.

Essa última - a do art. $14, \S 1^{\circ}$, da Lei n. 6.839/1981 - terá sido a hipótese de Brumadinho, a se demonstrar que os variados desvios e irregularidades identificados acima configuraram o que a Convenção da Organização Internacional do Trabalho n. 174 identifica como acidente maior, a saber,

[...] todo evento inesperado, como uma emissão, um incêndio ou uma explosão de grande magnitude, no curso de uma atividade dentro de uma instalação exposta a riscos de acidentes maiores, envolvendo uma ou mais substâncias perigosas e que exponha os trabalhadores, a população ou o meio ambiente a perigo de consequências imediatas ou de médio e longo prazos (art. $3^{\circ}, d$, grifo do autor).

Vale lembrar que por substância perigosa deve-se entender "toda substância ou mistura que, em razão de propriedades químicas, físicas ou toxicológicas, seja uma só ou em combinação com outras, represente perigo" 
(art. $3^{\circ}, a$ ); e que lama em profusão seguramente pode ser assim definida. Outrossim, ainda que não caiba a exata subsunção dos eventos de Brumadinho ao conceito de acidente maior (embora, a nosso sentir, deva caber), também terá sido a hipótese do art. $14, \S 1^{\circ}$, da Lei n. 6.938/1981, se aqueles desvios e irregularidades definiram incremento de risco análogo ao reportado pelas alíneas c e d do art. $3^{\circ}$ da Convenção n. 174. Isto tudo, ademais, a se supor que a mera existência de uma barragem já não permita migrar, de plano, para a hipótese de risco inerente superlativo (art. 927, par. único, Código Civil), dispensando qualquer discussão sobre ter havido ou não poluição para os efeitos do art. 3º, III, da Lei n. 6.938/1981 (o que, convenha-se, certamente houve, ante a base antrópica da degradação, ainda que não tenha havido culpa - e culpa, de resto, também parece ter claramente havido, restando apenas individualizá-la). Eis o que haverá de ser discutido judicialmente.

Há mais, porém. O Brasil assumiu internacionalmente a responsabilidade de isolar áreas residenciais e laborais das instalações expostas a riscos de acidentes maiores, nos termos do art. 17 da Convenção da Organização Internacional do Trabalho n. 174:

\footnotetext{
A autoridade competente deverá estabelecer uma política global de localização que tenha prevista uma separação adequada entre as instalações que estiverem expostas a riscos de acidentes maiores e as áreas de trabalho, as áreas residenciais e os serviços públicos, e medidas apropriadas para as instalações existentes. Tal política deverá refletir-se nos princípios gerais enunciados na Parte II desta Convenção.
}

Ocorre que, pelo que se descreveu, as áreas de trabalho e residenciais decerto não estavam adequadamente separadas da zona de impacto imediato de um possível acidente maior envolvendo a barragem 1 da Mina Córrego do Feijão. Ao contrário, estavam todos no curso provável da lama. Se a autoridade competente se omitiu - algo que aqui poderá implicar ao município ou ao estado, a depender do nível de fiscalização negligenciado, mas que implicará sobretudo a União, à vista das competências da Agência Nacional de Águas (art. 4, XX a XXII, da Lei n. 9.984/2000) e da natureza do órgão fiscalizador previsto pelo art. 16 da Lei n. 12.334/2010 (no âmbito de uma política nacional) -, a responsabilidade civil da Administração Pública poderá ser igualmente evocada, em favor dos lesados e de suas famílias, também em regime de responsabilidade civil objetiva (agora nos termos do art. $37, \S 6^{\circ}$, da Constituição Federal).

O tempo mostrará os caminhos. 


\section{CONCLUSÃO}

Desde o lançamento da cadeira Saúde, Ambiente e Trabalho I: Novos Rumos para a Regulamentação na pós-graduação da Faculdade de Direito da Universidade de São Paulo, temos insistido em que, pela configuração constitucional do meio ambiente do trabalho como parte integrante do meio ambiente humano, os princípios jurídicos de regência do direito ambiental devem necessariamente se aplicar às questões de saúde e segurança do trabalho, com especial destaque para o princípio da prevenção, o princípio da precaução, o princípio da melhoria contínua, o princípio da informação, o princípio da participação e o princípio do poluidor-pagador. Aplicam-se, mais, naquilo que for compatível, as leis que regem a proteção do meio ambiente, e em especial a Lei n. 6.938/1981.

Nessa perspectiva, tampouco os acidentes industriais maiores - como o que assolou Brumadinho no trágico dia 25 de janeiro de 2019 - poderão ser corretamente avaliados e tratados, se não o forem à luz dos princípios jurídicos acima relacionados. Por essa ótica é que se reconhece, tendo em conta as ideias de prevenção/precaução, que a exposição de trabalhadores a riscos incrementados deveria ter sido prioritariamente eliminada ou neutralizada, pela separação adequada entre as instalações expostas a riscos de acidentes maiores e os espaços residenciais e laborais. Já onde a eliminação e a neutralização não pudesse ocorrer prontamente, deveriam ter curso todas as medidas adequadas para que os riscos fossem progressivamente diminuídos (princípio da melhoria contínua ou do risco mínimo regressivo: art. $7^{\circ}$, XXII, Constituição Federal) - a começar pela adoção de outro método construtivo das barragens, o alteamento a jusante - e plenamente informados aos trabalhadores (princípio da informação), oportunizando diálogo permanente sobre as melhores estratégias de segurança ambiental laboral (princípio da participação).

Não foi assim, porém. Consumaram-se sérios danos ambientais ou pessoais decorrentes do desequilíbrio ambiental laboral, o que agora atrai o princípio do poluidor-pagador, impondo ao empregador a obrigação ex delicto de reparar os danos que sua atividade causou, independentemente de culpa ou dolo. Em outras palavras, se o empregador-poluidor não evita a concreção dos riscos que criou ou incrementou, deve ser responsabilizado objetivamente. E, diga-se, sem as absurdas peias quantitativas introduzidas pela Lei n. 13.467/2017, pelas exatas razões que a Associação Nacional dos Magistrados da Justiça do Trabalho vazou na petição inicial da Ação 
Direta de Inconstitucionalidade n. 6050/DF, sob a relatoria do Ministro Gilmar Mendes.

Na sociedade de riscos hipertrofiados do século XXI, a adoção das premissas do direito ambiental para o trato das questões de saúde e segurança do trabalho é vital e inadiável. Significará, a médio e longo prazos, reverter externalidades econômicas, combalindo a sólida cultura da contabilização dos danos ambientais e pessoais como variáveis imanentes às equações financeiras da atividade empresária. Significará internalizar os efeitos positivos da Convenção da Organização Internacional do Trabalho n. 174, ainda hoje uma mera declaração de intenções, pela própria impermeabilidade das autoridades administrativas e judiciárias. Significará, talvez, prevenir novas Brumadinhos.

É passado o tempo das ideias fáceis. Há que as recompilar, à mercê das lições da realidade. E, por fim, fazer o que o grande Goethe (1749-1832) supunha ser o mais difícil: agir conforme pensamos.

\section{REFERÊNCIAS}

BRASIL. Constituição (1988). Constituição da República Federativa do Brasil. Brasília: Senado Federal, Centro Gráfico, 1988. Disponível em: http://www.planalto.gov.br/ccivil_03/Constituicao/Constituiçao.htm. Acesso em: 18 nov. 2019.

BRASIL. Código de Processo Civil (2002). Lei n. 10406, de 10 de janeiro de 2002. Institui o Código de Processo Civil. Disponível em: http://www. planalto.gov.br/ccivil_03/leis/2002/110406.htm. Acesso em: 18 nov. 2019.

BRASIL. Norma Regulamentadora n. 1, de 1978. Disposições gerais. Disponível em: https://enit.trabalho.gov.br/portal/images/Arquivos_SST/ SST_NR/NR-01.pdf. Acesso em: 18 nov. 2019.

BRASIL. Norma Regulamentadora n. 9, de 1978. Programa de Prevenção de Riscos Ambientais. Disponível em: https://enit.trabalho.gov.br/portal/ images/Arquivos_SST/SST_NR/NR-09.pdf. Acesso em: 18 nov. 2019.

BRASIL. Norma Regulamentadora n. 15, de 1978. Atividades e operações insalubres. Disponível em: https://enit.trabalho.gov.br/portal/images/ Arquivos_SST/SST_NR/NR-15.pdf. Acesso em: 18 nov. 2019.

BRASIL. Código do Processo Civil (1981). Lei n. 6938, de 31 de agosto de 1981. Dispõe sobre a Política Nacional do Meio Ambiente, seus fins e 
mecanismos de formulação e aplicação, e dá outras providências. Disponível em: http://www.planalto.gov.br/ccivil_03/Leis/L6938.htm. Acesso em: 18 nov. 2019.

CARDOZO, F. A. C.; PIMENTA, M. M.; ZINGANO, A. C. Métodos construtivos de barragens de rejeitos de mineração: uma revisão. Holos, Natal, ano 32, v. 8, p. 77-85, 2017. Disponível em: www2.ifrn.edu.br/ojs/index. php/HOLOS/article/download/5367/pdf. Acesso em: 18 nov. 2019.

CENTRO DE ESTUDOS JUDICIÁRIOS DO CONSELHO DA JUSTIÇA FEDERAL. Enunciado 38. In: I JORNADA DE DIREITO CIVIL, $1 .$, 2002, Brasília. Anais [...]. Brasília: Conselho da Justiça Federal, 2002. p. 43. Disponível em: https://www.cjf.jus.br/cjf/CEJ-Coedi/jornadas-cej/ Jornada\%20de\%20Direito\%20Civil\%201.pdf/view. Acesso em: 18 nov. 2019.

CLERC, J. M. Training as an instrument of a strategy for the improvement of working conditions and environment. International Labour Review, v. 121, p. $565,1982$.

DERANI, C. Direito Ambiental Econômico. 3. ed. São Paulo: Saraiva, 2008.

FELICIANO, G. G. Meio ambiente do trabalho: aspectos gerais e propedêuticos. Revista do Tribunal Regional do Trabalho da $15^{a}$ Região, Campinas, n. 20, p. 160-203, jul./set. 2002.

FELICIANO, G. G. O meio ambiente do trabalho e a responsabilidade civil patronal: reconhecendo a danosidade sistêmica. Direito Ambiental do Trabalho, São Paulo, v. 1, p. 11-25, 2013.

FELICIANO, G. G.; URIAS, J.; MARANHÃO, N. (coord.). Direito Ambiental do Trabalho: apontamentos para uma teoria geral. São Paulo: LTr, 2017.

MACHADO, P. A. L. Direito Ambiental brasileiro. 18 ed. São Paulo: Malheiros, 2010.

MARANHÃO, N. Meio ambiente do trabalho: descrição jurídico-conceitual. In: FELICIANO, G. G.; URIAS, J.; MARANHÃO, N. (coord.). Direito Ambiental do Trabalho: apontamentos para uma teoria geral. v. 3. São Paulo: LTr, 2017, p. 27-40. 
MELO, R. S. Direito ambiental do trabalho e a saúde do trabalhador. 5. ed. São Paulo: LTr, 2013.

MIRANDA, P. Tratado de Direito Privado. São Paulo: Revista dos Tribunais, 2012.

NORTH, A. Desabamento em Bangladesh revela lado obscuro da indústria de roupas. BBC Brasil, 28 abr. 2013. Disponível em: https://www.bbc. com/portuguese/celular/noticias/2013/04/130428_bangladesh_tragedia lado_obscuro.shtml. Acesso em: 18 nov. 2019.

OLIVEIRA, S. G. Proteção jurídica à saúde do trabalhador. 2. ed. São Paulo: LTr, 1998.

ONU - ORGANIZAÇÃO DAS NAÇÕES UNIDAS. Declaração de Estocolmo sobre o ambiente humano de 1972. 1972. Disponível em: http:// www.direitoshumanos.usp.br/index.php/Meio-Ambiente/declaracao-de-estocolmo-sobre-o-ambiente-humano.html. Acesso em: 18 nov. 2019.

ONU - ORGANIZAÇÃO DAS NAÇÕES UNIDAS. Declaração do Rio sobre meio ambiente e desenvolvimento. 1992. Disponível em: http://www. onu.org.br/rio20/img/2012/01/rio92.pdf. Acesso em: 10 set. 2017.

OIT - ORGANIZAÇÃO INTERNACIONAL DO TRABALHO. Convenção n. 155, de 3 de junho de 1981. Segurança e saúde dos trabalhadores. Disponível em: https://www.ilo.org/brasilia/convencoes/WCMS_236163/ lang--pt/index.htm. Acesso em: 18 nov. 2019.

OIT - ORGANIZAÇÃO INTERNACIONAL DO TRABALHO. Convenção n. 161, de 7 de junho de 1985. Serviços de saúde no trabalho. Disponível em: https://www.ilo.org/dyn/normlex/en/f?p=NORMLEXPUB:12100:0::NO:12100:P12100_INSTRUMENT_ID:312306:NO. Acesso em: 18 nov. 2019 .

OIT - ORGANIZAÇÃO INTERNACIONAL DO TRABALHO. Convenção $n$. 174, de 2 de junho de 1993. Prevenção de acidentes industriais maiores. Disponível em: https://www.ilo.org/dyn/normlex/en/f?p=NORMLEXPUB:12100:0::NO:12100:P12100_INSTRUMENT_ID:312319:NO. Acesso em: 18 nov. 2019.

PADILHA, N. S. Meio ambiente do trabalho: um direito fundamental do trabalhador e a superação da monetização do risco. Revista do Tribunal Superior do Trabalho, Brasília, DF, v. 79, n. 4, p. 173-182, out./dez. 2013. 
PADILHA, N. S. Do meio ambiente do trabalho equilibrado. São Paulo: LTr, 2002.

PASSARELLI, H. Tipo de barragem usado em MG é inadequado ao clima, diz especialista. Valor Econômico, 30 jan. 2019. Disponível em: https:// www.valor.com.br/brasil/6097651/tipo-de-barragem-usado-em-mg-e-inadequado-ao-clima-diz-especialista. Acesso em: 18 nov. 2019.

PINTO, M. El principio pro homine: criterios de hermeneutica y pautas para la regulación de los derechos humanos. In: La aplicación de los tratados de derechos humanos por los tribunales locales. Buenos Aires: Editorial del Puerto, 1997. p. 163-172.

PRIEUR, M. Droit de l'environnement. 4. ed. Paris: Dalloz, 2001.

ROSSI, A. Tragédia em Brumadinho: Vale diz que sirenes não foram acionadas por 'velocidade' do deslizamento. BBC Brasil, 31 jan. 2019. Disponível em: https://www.bbc.com/portuguese/brasil-47063312. Acesso em: 18 nov. 2019.

Artigo recebido em: 13/06/2019.

Artigo aceito em: 31/10/2019.

\section{Como citar este artigo (ABNT):}

FELICIANO, G. G.; PASQUALETO, O. Q. F. Meio ambiente laboral equilibrado: análise do caso Brumadinho. Veredas do Direito, Belo Horizonte, v. 16, n. 36, p. 191-216, set/dez. 2019. Disponível em: http://www. domhelder.edu.br/revista/index.php/veredas/article/view/1556. Acesso em: dia mês. ano. 